\title{
A organização social do trabalho doméstico e de cuidado: considerações sobre gênero e raça
}

The social organization of care and domestic work: considerations on gender and race

\author{
Cíntia Engel ${ }^{*}$ \\ Bruna C. J. Pereira**
}

\begin{abstract}
Resumo
Este artigo tem por intento observar como a raça, enquanto categoria social, constituise como eixo articulador da organização social do trabalho doméstico e de cuidado no Brasil. Iniciamos o texto com a retomada de discussões sobre a Divisão Sexual do Trabalho, tendo em conta a produção dos estudos feministas e de gênero que se ocupam da temática. Dando prosseguimento, procuramos apreender a associação simbólica das mulheres negras ao servir e ao cuidar em uma narrativa largamente aceita sobre a identidade nacional. Adiante, fazemos uma apresentação de dados sobre a associação das mulheres negras ao trabalho doméstico. Finalmente, nos debruçamos sobre reflexões, conexões e caminhos interpretativos possíveis.
\end{abstract}

\begin{abstract}
This article aims to observe race - understood as a social category - as an axes along of which domestic labor and the work of care are structured in Brazil. First, we resume the recent debate on Sexual Division of Labor, taking into account feminist and gender studies and propositions. Next, we seek to grasp the symbolic association of black women to servitude and care work in a widely accepted narrative about national identity. Following, we present data on the association of black women to domestic labor. Finally, we present some considerations, connections and possible interpretive paths.
\end{abstract}

Palavras-chave: cuidado; trabalho doméstico; gênero; raça; mulheres negras.

Keywords: care, domestic labor, gender, race, black women.

\footnotetext{
* Mestra em Sociologia pela Universidade de Brasília (UnB), coordenadora de Pesquisa do Departamento de Pesquisa, Análise da Informação e Desenvolvimento de Pessoal em Segurança Pública da Secretaria Nacional de Segurança Pública do Ministério da Justiça.

** Mestra em Sociologia pela Universidade de Brasília (UnB) e pesquisadora do Núcleo de Estudos e Pesquisas sobre a Mulher (NEPeM/UnB).
} 


\section{Introdução}

O objetivo deste artigo é apresentar reflexões e elencar dados que permitam observar a operação da raça, entendida como categoria social, como "princípio regulador da provisão de care" (Sorj e Fontes, 2012:105) no contexto brasileiro. Para tanto, propomos discussões de cunho teórico-conceitual entre determinada bibliografia sobre cuidados e certa vertente dos estudos sobre relações raciais no Brasil, de maneira a jogar luz em questões ainda pouco exploradas, porém estruturantes na organização social do care. Resgatamos inicialmente conceitos e argumentos caros à bibliografia sobre cuidados, aos quais contrapomos, em seguida, representações racializadas do trabalho doméstico e de cuidados presentes no imaginário hegemônico sobre identidade nacional, conforme codificadas em obras clássicos dos estudos sobre relações raciais. Com o intuito de observar transformações e continuidades, elencamos então dados atualizados sobre o desempenho dos cuidados no Brasil, seguidos de algumas propostas iniciais, formuladas a partir do exercício proposto.

Como será visto no decorrer do texto, propomos que gênero e raça fazem parte de uma lógica complementar de manutenção da divisão sexual do trabalho e constroem hierarquias próprias de atribuições de funções e papéis de reprodução social. Para construir nossa argumentação, ateremo-nos ao desempenho dos afazeres domésticos e de cuidado, que serão abordados tanto pela promoção de uma discussão simbólica sobre o lugar das mulheres negras na narrativa hegemônica de formação da identidade nacional, quanto por meio de dados quantitativos que revelam a histórica concentração de mulheres negras em tarefas de cuidado. Antes de adentrar a discussão central à qual nos dedicamos, exporemos brevemente alguns dos temas e abordagens centrais para os debates atuais sobre o care.

\section{Divisão Sexual do Trabalho: definições e contextos}

A bibliografia sobre cuidado utiliza, geralmente do termo care ou care work para definilo. O uso do termo em inglês é devido à influência anglo-saxã sobre tal produção, uma vez que a consolidação dos cuidados como um objeto de estudos ocorreu primeiramente nos países de língua inglesa. Ele deriva, ainda, da polissemia do termo, que dificulta uma tradução exata: care pode significar cuidado, solicitude, preocupação com o/a outro/a ou ainda atenção às necessidades do/a outro/a (Hirata, 2009: 42).

Contudo, não há consenso sobre a terminologia mais adequada, seja porque a formulação dos conceitos não se mostra satisfatória a pesquisadores/as que partem de perspectivas teóricas e interesses diversificados, seja devido à complexidade do fenômeno, que comporta dimensões distintas (Carrasco; Borderías; Torns, 2011: 71). Afinal,

o conceito de care engloba, com efeito, uma constelação de estados físicos ou mentais e de atividades trabalhosas ligadas à gravidez, criação e educação das crianças, aos cuidados com as pessoas, ao trabalho doméstico e, de forma mais 
abrangente, qualquer trabalho realizado a serviço das necessidades dos outros. (Molinier, 2004: 227).

A dificuldade de captar todos esses estados em uma única definição e as ambiguidades quanto aos termos empregados contribuem para a existência de divergências quanto aos conteúdos considerados como pertinentes ao cuidado ou care, assim como sobre o seu significado e natureza. Tendo em vista os intuitos deste artigo, aderimos a um conceito ampliado dos cuidados - termo que será utilizado de maneira intercambiável com "cuidado", "trabalho reprodutivo", "trabalhos de reprodução social", "trabalhos de cuidado" e "care". Pretendemos com isso facilitar uma visão panorâmica da organização social do cuidado e de como os sujeitos se envolvem nessas complexas relações, por meio do diálogo com perspectivas teórico-conceituais e escolas diversas, que se utilizam de termos específicos. O foco então é no cuidado ou care como prática, assim, são consideradas como pertinentes ao care aquelas atividades, qualidades e disposições relacionadas ao trabalho reprodutivo, desempenhadas de forma remunerada ou não, que demandam ou não a interação face a face e o vínculo afetivo, que são direcionadas a pessoas dependentes e autônomas, e que se voltam para a reprodução e para o bemestar de todos os indivíduos e sociedades.

Os trabalhos de cuidado envolvendo a casa e as pessoas são fundamentais para a manutenção das lógicas de funcionamento dos lares. Trazer à tona o debate sobre a divisão dos trabalhos de cuidado não é uma iniciativa nova: os estudos feministas têm se ocupado bem em demonstrar, por meio de uma série de metodologias quantitativas e qualitativas, além de propostas teórico-conceituais, como as divisões de tarefas entre homens e mulheres representam uma das principais consequências cotidianas da atribuição dos papéis e funções relativas às relações de gênero.

Historicamente, estudiosas francesas insistiram muito no termo "Divisão Sexual do Trabalho", utilizado como referência às atribuições de trabalho entre homens e mulheres, estas responsáveis diretas pelo cuidado com a casa, com os filhos e com a reprodução social de todos os membros da residência. Para Helena Hirata e Danièle Kergoat, o termo pode ser resumido como:

A divisão sexual do trabalho é a forma de divisão do trabalho social decorrente das relações sociais entre os sexos: mais do que isso, é um fator prioritário para a sobrevivência da relação social entre os sexos. Essa forma é modulada histórica e socialmente. Tem como características a designação prioritária dos homens à esfera produtiva e das mulheres à esfera reprodutiva e, simultaneamente, a apropriação pelos homens das funções com maior valor social adicionado (políticos, religiosos, militares, etc.)(Hirata e Kergoat, 2007: 5).

Além dos estudos sobre divisão sexual do trabalho, o termo "reprodução social" também é bastante conhecido dos estudos de gênero, indicando a função que atividades de cuidado e manutenção da casa e das pessoas têm na reprodução das lógicas sociais, afetivas e financeiras e pode ser descrito como "o conjunto de atividades e relações envolvidas em manter as pessoas, tanto no plano do dia a dia quanto intergeracionalmente" (Glenn, 1992: 1). 
Recentemente, os estudos sobre o trabalho de care têm retomado com peso o foco nas discussões sobre as divisões de tarefas de cuidado e atentado para as novas configurações de atendimento das necessidades dos indivíduos, inclusive investigando soluções encontradas pelo mercado e pelo Estado para suprir tais serviços. Leva-se em consideração a existência de uma crescente população envelhecida que demanda cuidados específicos, aliada à prevalência de famílias menores, com mulheres ocupadas de trabalhos no mercado e pouco disponíveis para o exercício das funções de atenção ao outro. As reflexões sobre o cuidado retomam sua centralidade e chamam atenção para as tensões, estratégias e dilemas em mantê-lo e em como fazer isso.

$\mathrm{Na}$ gama dos estudos recentes sobre o care, encontram-se diferentes trabalhos e propostas de estudos (Hirata e Guimarães, 2012). Alguns deles continuam a se aproximar da ideia de reprodução social e discutem com maior atenção as divisões sexuais de trabalho envolvidas (Hirata e Kergoat, 2007; Melo, Considera e Di Sabbato, 2007) e também as implicações que as lógicas simbólicas e hierárquicas de gênero têm no desenvolvimento desses trabalhos - como no caso dos estudos específicos sobre usos do tempo(Fontoura, 2010; Aguiar, 1981; Bandeira, 2010). Em conjunto, existem iniciativas dedicadas às análises dos discursos produzidos acerca do cuidado e de sua relação direta com os símbolos envolvendo feminilidade e concepções de cuidado (Molinier, 2004; Lagarde, 2003).

A discussão volta-se também para um novo campo das relações de trabalho. Nesse caso, aborda-se o crescimento na área dos serviços destinados às pessoas e a consequente diversificação dos trabalhos disponíveis. $\mathrm{O}$ afeto e cuidado ao outro tem representado boa parte das demandas contemporâneas por serviços - essas envolvendo desde os vários serviços de cuidado direto com as pessoas (Hochschild, 2003), até aqueles que providenciam espaços de interação erótico-afetiva ${ }^{1}$. Essa linha de estudos desenvolve análises específicas relativas ao trabalho de care e suas implicações nas relações de trabalho e nas subjetividades envolvidas nesse labor afetivo.

Outros estudos investem maior fôlego nas políticas de cuidado desenvolvidas pelos Estados, suas limitações e paradigmas principais. Nesse quesito, existem comparações entre países que possuem políticas de cuidado já implementadas (Lisboa, 2007; Glucksmann, 2012; Gutiérrez-Rodríguez, 2012) e, o que nos interessa de forma particular, reflexões específicas sobre a resistência em estabelecer contextos apropriados para o desenvolvimento igualitário das reproduções sociais e políticas de cuidado. Estudos sobre Estados latino-americanos apontam para um histórico de políticas intensificadoras do apoio da instituição familiar, entendida política e simbolicamente como espaço nuclear ideal e responsável pela reprodução dos sujeitos (Arriagada, 2005; Sunkel, 2006).

\footnotetext{
${ }^{1}$ Parreñas (2012) observa o trabalho de mulheres que acompanham e participam de interações e flertes com homens, dentro de clubes próprios para isso. As acompanhantes agem como se estivessem interessadas e participam de um jogo inicial de conquista, o que por vezes leva à troca de telefonemas e flertes que perduram por dias, embora não haja, na maioria dos casos, relações sexuais. Esse é considerado um trabalho de cuidado pela disposição de tempo e atenção para com o bem-estar dos clientes.
} 
No Brasil, algumas estudiosas compartilham de uma visão que poderíamos definir como paradigma brasileiro de cuidado (Camarano, 2007; 2012). Nosso país não possui políticas específicas de cuidado; suas iniciativas - como creches e atendimentos domiciliares a pessoas com idade avançada -, constituem-se de ações limitadas em espaço, tempo e contingente. Além disso, funcionam como auxílios muito específicos e não como uma política constante e extensiva de cuidado.

A principal saída vislumbrada pelas classes médias e altas tem sido, historicamente, a contratação de empregadas domésticas e babás, mais recentemente, e cuidadoras de idosos. As mulheres de classes baixas fornecem a principal mão de obra para esses serviços (Sorj, 2010) e também estão ocupadas com outras atividades nas esferas do mercado; ao mesmo tempo, são destituídas dos tempos de cuidado interno, ou contam com troca de favores entre vizinhos e pessoas aparentadas fora do núcleo familiar principal para suprir demandas de reprodução social. Dados sugerem que as classes altas e médias são "as mais cuidadas" no Brasil. Bila Sorj e Adriana Fontes (2012) divulgam, com base nos dados da POF 2008-2009, que as classes altas contam com auxílio externo para a manutenção de atividades de cuidado com a casa e com as pessoas em uma porcentagem alta dos casos: $51,7 \%$ dos lares de renda mais alta gastam com a contratação de terceiros, número que aumenta para $73 \%$ no caso de famílias com filhos menores de 6 anos. Em comparação, nos lares de menor renda essa opção é quase inexistente: a porcentagem reduz-se para $2,2 \%$ e tem um aumento para $2,4 \%$ no caso de famílias com filhos menores de 6 anos.

Essa configuração gera uma série de consequências para as famílias de classes baixas - e principalmente para as mulheres. Se mulheres de todas as classes sociais são sobrecarregadas pela responsabilidade de cuidado e das atividades básicas de reprodução social, são as mulheres pobres que atendem a essa demanda do mercado de trabalho, limitando suas possibilidades de escolha profissional e investindo-se em repetidos turnos sob os mesmos afazeres para dar conta da casa onde recebem salário e de suas próprias residências.

Em trabalho recente sobre a divisão de cuidados, Hirata e Kergoat (2007) sugerem que as mudanças sociais relativas às mulheres e à ocupação de espaços públicos revolucionaram os postos que elas podem ocupar nomercado de trabalho, promoveram maior liberdade sexual e de relacionamento, dentre outras. Contudo, em termos estatísticos, a divisão de tarefas de cuidado e reprodução social sofreu poucas modificações - as mulheres continuam responsáveis principais por tais funções.

A inserção dos homens nas tarefas de reprodução social ainda é muito pouco representativa em distintas realidades. O quantitativo de horas empregadas pelos homens nas tarefas domésticas sugere a falta de uma divisão abrangente de trabalho com os mesmos, principalmente no que se refere a pesquisas desenvolvidas com base em núcleos familiares heterossexuais e com filhos ${ }^{2}$.

\footnotetext{
${ }^{2}$ Segundo pesquisa da FDA (2001), no caso do Brasil, as mulheres mais ocupadas de tarefas domésticas eram aquelas envolvidas em relações maritais. Essas gastavam, em média, 48 horas semanais com tais funções; seus maridos 5 horas semanais. A média era menor para mulheres de maneira geral - com 39 horas gastas.
} 
Uma consequência da falta de modificações na estrutura de divisão de tarefas de reprodução social entre homens e mulheres - aliada ao aumento do trabalho destas foi o acirramento das hierarquias funcionais entre as mulheres. Conforme observado por Hirata e Kergoat, a possibilidade de que certo grupo de mulheres exerça funções públicas e continue mantendo lares familiares com funções de reprodução está diretamente conectada à delegação destas. Ao mesmo tempo em que cresce o número de mulheres com formação acadêmica e bons empregos na esfera pública, aumenta a quantidade de mulheres em empregos precarizados e diretamente relacionados com a manutenção da esfera privada.

As autoras estão se referindo à realidade europeia, analisando ainda uma etnicização das delegações de tarefas. Essas mulheres de países desenvolvidos, bem formadas e com bons empregos, além de disporem do trabalho de mulheres francesas em situações de baixa renda, importam outras mulheres (latinas, africanas, da Europa oriental, etc.) para dar conta das tarefas domésticas. Essas imigrantes deixam de atender seus lares e seus filhos para aumentar sua renda e suprir financeiramente suas famílias (Duffy, 2007; Lisboa, 2007; Gutiérrez-Rodríguez, 2012; Parreñas, 2012).

O trabalho de outras mulheres é necessário para que europeias, brancas e de renda alta consigam sustentar a lógica de funcionalidade reprodutiva de uma família heteronormativa clássica, com existência de filhos; ou, mais recentemente, de idosos que necessitam de cuidados. A lógica de funcionamento de uma família assim configurada demanda atenção e tempo de cuidado que não podem ser supridos sem a dedicação específica de uma ou várias pessoas e de seu(s) trabalho(s) repetido(s) nessas funções. Nesse sentido, existe um crescimento de demanda por tais serviços. A lógica de divisão de tarefas de reprodução social continua estruturando cotidianos e intensificando relações de gênero; continua, além disso, a intensificar posições hierárquicas entre mulheres.

No caso do Brasil, a delegação de tarefas entre mulheres remonta aos primórdios de nossa constituição histórica. Mulheres negras e indígenas foram e têm sido demandadas como mão de obra escrava ou precarizada na realização das funções domésticas. A racialização dessas relações no Brasil apresenta sobreposições e também divergências em relação à etnicização de cuidados presente no texto de Hirata e Kergoat e em muitos outros aqui citados.

A discussão mencionada sobre o trabalho de cuidado aponta para uma divisão de tarefas entre mulheres no que se refere à classe. O recorte racial, por sua vez, tem suscitado pouco interesse no que se refere ao tema, talvez pelo pressuposto de que a questão racial poderia ser esgotada na questão de classe, dado o processo histórico de formação das subalternidades brasileiras. Sem deixar de reconhecer os avanços obtidos pela tendência analítica que privilegia a classe como categoria, entendemos que existem adicionalmente importantes lógicas raciais que regulam a distribuição social do trabalho de care, entendido como trabalho doméstico e de cuidado ao outro. Afinal, o sequestro, tráfico e escravização de africanos e a dominação genocida de populações indígenas deu início, entre outros, à exploração de sua mão de obra, sobretudo pela sua alocação junto às atividades de menor status social - no caso das mulheres, a limpeza e manutenção da 
casa e dos indivíduos. Cabe observar como aspectos dessa associação vêm transformando-se ou mantendo-se na sociedade brasileira contemporânea.

Um episódio recente é bastante ilustrativo da fixação simbólica sobre o exercício de funções domésticas. Uma jovem médica, branca, comentou de forma extremamente pejorativa em uma rede social que médicas cubanas negras ${ }^{3}$ pareciam-se com empregadas domésticas. O racismo brasileiro constitui-se a partir da articulação de subalternidades econômicas e funcionais, que se combinam à dimensão simbólica.

Atentamos então para o fato de que o processo histórico de formação da nação brasileira orquestrou-se articulando as divisões de poder e de trabalho entre mulheres. Como consequência, a constituição de identidades femininas comportaram - e comportam -diferentes realidades e hierarquias. Existem, portanto, anunciadas limitações em tratar de maneira indistinta as experiências subjetivas, sociais, econômicas e simbólicas das mulheres brancas e negras (pretas e pardas). Sem negar a existência de um status de gênero partilhado, sublinhamos a importância de que se considere a multidimensionalidade da experiência das mulheres e, especificamente, da observação de como distintas identidades raciais impactam a inserção social e as vivências de mulheres de diferentes grupos raciais.

Adiante, daremos continuidade à discussão proposta abordando com maior atenção como o trabalho doméstico e o cuidado, vinculados à raça, têm sido tratados no ideário brasileiro acerca da identidade nacional.

\section{Trabalho doméstico, cuidado e raça na formação da identidade nacional}

Diversos autores que tiveram suas obras consagradas como estudos clássicos do campo das Relações Raciais fazem menção a alguma forma de protagonismo das mulheres negras. Gilberto Freyre (2003), Roger Bastide (Bastide e Fernandes, 1955), Florestan Fernandes (1978) e Otávio lanni (1972) atribuíram a esse grupo de mulheres algum tipo de atuação social proeminente ${ }^{4}$, ainda que em setores e dimensões diversos. A despeito da existência de múltiplas perspectivas nos cânones das Relações Raciais, compreendemos que a apreensão da experiência social das mulheres negras como veiculada em Casa Grande e Senzala(Freyre, 2003), constitui um exercício capaz de alicerçar as reflexões a que nos propomos, tendo em vista o enfoque e a importância conferidos pelo autor às relações travadas no âmbito doméstico.

Dessa maneira, nos voltamos a resgatar a maneira como as mulheres negras aparecem representadas na obra em relação aos trabalhos de cuidado, com vistas a observar seu papel quanto a tais funções naqueles contextos. Vale a ressalva de que, para os propósitos desse artigo, não tomamos a obra como um relato etnográfico, mas sim como codificadora de um imaginário hegemônico sobre a formação nacional. Contemplaremos ainda as diferentes formas como são representadas mulheres negras e

\footnotetext{
${ }^{3}$ A jovem estava referindo-se ao Programa de Governo Mais Médicos (2013), que tem como objetivo abrir vagas para médicos/as brasileiros/as e estrangeiros/as para atuação na área de atenção básica no Norte e Nordeste, periferias de grandes cidades e municípios do interior em todas as regiões do Brasil.

${ }^{4}$ Sobre o tema, ver Maria Aparecida Silva Bento (1995), Sônia Giacomini (2006) e Laura Moutinho (2004).
} 
brancas, quanto às funções que desempenham, de maneira a descortinar nesta narrativa sobre o que se entende ser um momento fundante da sociedade brasileira a existência de uma divisão racial do trabalho reprodutivo. Com isso, esperamos embasar a observação de como e em que medida tal imaginário foi e é encarnado na organização social do cuidado. Por esse motivo, essa seção está diretamente vinculada com a próxima, se aqui trazemos essa narrativa, no momento seguinte discutimos dados concretos sobre a organização social do care no Brasil.

A obra em questão foi publicada pela primeira vez no ano de 1933 e figura ainda hoje nas ciências sociais como leitura indispensável para a compreensão da construção de uma identidade nacional e também para o entendimento das relações raciais brasileiras. No livro, o autor expressa a sua preocupação em recuperar o que chama de "formação da família brasileira", detendo-se, com esta finalidade, nos parâmetros e configurações assumidos pelas relações sociais peculiares ao cenário rural do sistema escravista. Propondo-se a fornecer uma perspectiva culturalista (contraposta a vieses sociológicos apoiados na biologia), Freyre buscou traçar uma genealogia de hábitos e formas culturais que derivariam, em sua visão, do hibridismo das culturas indígena, africana e portuguesa.

Essencialmente, Casa Grande e Senzala dedica-se a um olhar descritivo e explicativo das relações interpessoais travadas no âmbito doméstico. A constelação familiar em foco é formada pelo grupo branco e proprietário, em torno da qual orbitam, avulsos/avulsas, os/as trabalhadores/as negros/as e indígenas. A abordagem da experiência social desses sujeitos não se dá quanto aos seus próprios afetos e relações de parentescos, e sim reduz-se ao seu contato com a família branca. Afinal, no entendimento do autor, a casagrande é completada pela senzala (Freyre, 2003: 36). A senzala, como espaço físico ocupado exclusivamente pelos/as escravos/as e como espaço simbólico representativo do conjunto de relações familiares dos/das negros/negras, está subordinada às demandas e lógicas inerentes à família patriarcal branca.

As mulheres negras, cujas práticas sociais aparecem na obra como desvinculadas de regras e padrões característicos da família patriarcal branca (Giacomini, 2006) figuram como mediadoras, como "elo de ligação" entre a população branca e a população negra, a "pedra fundamental da miscigenação" - que constitui, por sua vez, a base da possibilidade de uma identidade nacional brasileira.

Na constelação da família patriarcal um segundo papel social é protagonizado pelas mulheres negras, cabem a elas as tarefas de cuidado e afeto, bem como toda a execução do trabalho doméstico necessário à manutenção do bem-estar da família patriarcal branca na casa-grande. Destaca-se a relevância atribuída às atividades de cuidado desempenhadas pelas amas negras, que, de acordo com Freyre, constituíram as bases de uma efetiva miscigenação das culturas portuguesa e africana. Como responsáveis pela socialização das crianças brancas, as amas negras teriam propiciado o seu contato também com a cultura africana, disseminando assim entre a população branca cosmovisões distintas da europeia. 
Contudo, não foram apenas as crianças as beneficiárias diretas das tarefas domésticas e de cuidado desempenhadas pelas mulheres negras. Freyre descreve uma família patriarcal branca que se acostumou a ser servida em suas mais singelas necessidades cotidianas:

Escravos que se tornaram literalmente os pés dos senhores: andando por eles, carregando-os de rede ou de palanquim. E as mãos - ou pelo menos as mãos direitas; as dos senhores se vestirem, se calçarem, se abotoarem, se limparem, se catarem, se lavarem, tirarem os bichos dos pés (Freyre, 2003: 385).

Como resultado, o trabalho das mulheres negras tinha como contrapartida para brancos e brancas a predominância de vivências pautadas pelo ócio: "Os dias se sucediam iguais; a mesma modorra; a mesma vida de rede, banzeira, sensual. E os homens e as mulheres, amarelos, de tanto viverem deitados dentro de casa e de tanto andarem de rede ou de palanquim." (Freyre, 2003: 387). Percepção que se confirma no relato de viajantes estrangeiros em suas visitas ao Brasil:

Todo o serviço doméstico é feito por pretos: um cocheiro preto quem nos conduz, uma preta que nos serve, junto ao fogão, o cozinheiro é preto e a escrava amamenta a criança branca; gostaria de saber o que fará essa gente quando for decretada a completa emancipação dos escravos (Von Binzer apud Kofes, 2001: 134).

Não se pode dizer que o ócio a que se refere Freyre fosse suficiente para igualar o status social e o conjunto de atividades atribuídas a homens e mulheres brancos. As diferentes prerrogativas de sua inserção social podem ser também encontradas nos escritos de Freyre. Especificamente sobre as mulheres brancas, diz o autor que as tarefas domésticas mais leves eram desempenhadas por elas de forma opcional, como antídoto ao tédio predominante para esse segmento numa sociedade em que todo o trabalho braçal foi relegado aos/às negros/as cativos/as, e em que os valores patriarcais, simultaneamente, restringiam as possibilidades de circulação das mulheres brancas fora da casa-grande e o escopo das atividades a que poderiam dedicar-se naquele ambiente rural e escravista:

[...] as brasileiras [brancas] envelheciam depressa; seu rosto tornava-se logo de um amarelo doentio.

Resultado, decerto, dos muitos filhos que lhes davam os maridos; da vida morosa, banzeira, moleirona, dentro de casa; do fato de só saírem de rede e debaixo de pesados tapetes de cor [...](Freyre, 2003: 428).

Casadas [as mulheres brancas], sucediam-se nelas os partos. Um filho atrás do outro. Um doloroso e contínuo esforço de multiplicação [...], deixando as mães uns mulambos de gente (Freyre, 2003: 445).

A reprodução social da família patriarcal branca, em sua dimensão biológica - isto é, como produção de corpos -, emerge na narrativa de Freyre como a tarefa das mulheres brancas por excelência. De fato, esta parece ser a única atividade social desempenhada 
exclusivamente por elas. O mesmo não se pode dizer quanto às mulheres negras, que, além de relacionadas primordialmente à satisfação sexual dos senhores e aos trabalhos domésticos e de cuidado, viam suas possibilidades de reprodução bastante restritas em virtude das péssimas condições de alimentação e abrigo de que dispunham, bem como do trabalho árduo a que estavam submetidas mesmo durante os períodos de gravidez (Giacomini, 1988).

Ao recuperar dos escritos de Freyre os papéis sociais desempenhados por mulheres brancas e negras, é possível vislumbrar que o seu status compartilhado de gênero está atravessado de forma drástica pelos demarcadores raciais. Na sociedade que o autor descreve, a diferença entre ser mulher branca ou negra é imensa, pois cada uma está destinada a papéis muito distintos, e que reservam a cada um desses grupos tarefas específicas.

Cabe ainda destacar que a atribuição de diferentes lugares e papéis sociais para brancas e negras não se dá apenas como indicação de diferença, do vislumbre de identidades sociais distintas, e sim como classificação hierárquica (Moreira, 2007). Na sociedade escravista, o trabalho manual era visto como desqualificado e aviltante. Assim, não é irrelevante que o trabalho doméstico e de cuidado da casa-grande tenha sido atribuído exclusivamente às mulheres negras e vetado às mulheres brancas (Kofes, 2001). 0 convívio diário e a divisão de tarefas entre mulheres obedeciam a lógicas de dominação social, assentadas em relações de autoridade, dependência e hierarquia (Souza, 2012).

Simultaneamente, na obra de Freyre, os pressupostos que amparam o desempenho dos mencionados papéis para negras e brancas não apenas são distintos, como divergem também em sua natureza. Na perspectiva do autor, fica subentendido que o papel reprodutor das mulheres brancas decorre, sobretudo, de configurações sociais, e que o seu desempenho precoce e excessivo as prejudica em seu bem-estar físico (percepção que não se descola de uma suposta fragilidade do corpo feminino branco, em relação ao corpo feminino negro) e nas suas possibilidades de realização pessoal.

O mesmo não é observado quanto à abordagem da experiência social das mulheres negras. Embora pontue ocasionalmente crueldades de sinhôs e sinhás contra as cativas e perversidades inerentes ao regime escravista, o desgaste corporal e emocional decorrente do desempenho das atividades domésticas e de cuidado não parece, para Freyre, ter impactos negativos para as mulheres negras. Sua análise funda-se, portanto, na compreensão de que a estrutura física e a subjetividade das mulheres negras foram talhadas para o desempenho do trabalho doméstico e do cuidado.

A primazia da familiaridade e da proximidade entre brancos e negros - que caracterizam a descrição freyriana das relações sociais brasileiras e que teriam sido forjadas na casagrande - emerge mediante a supressão da complexidade das relações pessoais entre os sujeitos da família branca patriarcal e os escravos domésticos, sobretudo com as escravas domésticas. Contrapondo-se a esta visão romântica, alguns estudos historiográficos e sociológicos indicam que o cuidado desenvolveu-se e desenvolve-se sob fortes tensões e conflitos, em cenários nos quais de misturam vínculos de afeto, 
exploração e violência (Bernardino-Costa, 2012; Machado, 2012; Souza, 2012), e com desfechos quase sempre desfavoráveis às trabalhadoras.

O escrutínio das relações na casa-grande presta-se, tanto neste artigo como em Casa Grande e Senzala, à análise de dinâmicas sociais mais amplas. Para além das relações interpessoais, diretas e imediatas, o autor procura compreender o nascimento de uma identidade nacional, que é representada na obra pelo microcosmo da casa-grande. 0 que o instiga é a busca por uma genealogia de formações sociais que entende serem peculiarmente brasileiras. Dessa forma, a nossa referência a marcadores raciais que instituem clivagens nas identidades e papéis sociais dos sujeitos femininos tem a intenção de tornar visível a posição de centralidade que elas ocupam no ideário freyreano de nação brasileira. Para além do domínio da família e do domicílio, a forma como o trabalho doméstico e de cuidado organiza-se e distribui-se socialmente embasa o modelo privilegiado de reprodução social e também o que se entende por identidade nacional brasileira.

Seria precipitado supor que as análises desse autor sobre o modelo patriarcal, agrário e escravista de algumas famílias proprietárias, da elite, possam ser adotadas como referência da formação de uma identidade nacional e mesmo como uma etnografia representativa da sociedade brasileira da época. De fato, a escravidão doméstica compreendeu uma das principais modalidades de trabalho dos cativos, e as escravas tornaram-se figuras indispensáveis para a manutenção doméstica tanto dos lares simples, como dos abastados, durante todo o período colonial (Souza, 2012). Entretanto, as análises freyrianas são baseadas em um contexto social muito específico e restrito.

A análise de suas considerações justifica-se pela importância atribuída a esse autor na sistematização de um imaginário da nação e na sua influência simbólica inegável sobre a mesma. Freyre representa um exemplo ideal de representações simbólicas sobre o imaginário nacional das divisões do trabalho doméstico e de cuidado. Essas concepções não podem ser transpostas de forma imediata à sociedade brasileira, principalmente a atual. No hiato temporal que separa os dois períodos, fatos históricos como a abolição da escravidão, a industrialização, a urbanização, a implementação de políticas públicas eugênicas e de embranquecimento da população brasileira, bem como a mobilização política de distintos segmentos sociais, produziram transformações significativas tanto nas dinâmicas das relações raciais quanto na divisão social do trabalho. Especificamente quanto ao trabalho doméstico e de cuidado, as mudanças mais significativas podem ser observadas no perfil das trabalhadoras, nas modalidades de inserção no emprego e nos rearranjos da organização doméstica (Motta, 1992). A seguir, procuramos delinear o perfil da divisão racial do trabalho doméstico e de cuidados na sociedade brasileira contemporânea, de forma a observar continuidades e rupturas.

\section{A divisão racial do trabalho doméstico remunerado}

No Brasil, em 2009, 17\% das mulheres que compunham a população economicamente ativa o faziam na condição de trabalhadoras domésticas - setor de maior colocação feminina no mercado de trabalho até então. Em oposição, apenas $1 \%$ dos homens 
desempenhavam trabalho doméstico. Para além das desigualdades de gênero, as desigualdades raciais entre mulheres também eram marcantes. No mesmo ano, $21,8 \%$ das mulheres negras ocupadas eram trabalhadoras domésticas, contra $12,6 \%$ das mulheres brancas. Isso significa que mais de uma em cada cinco mulheres negras ocupadas inseriam-se no mercado de trabalho como prestadora de serviços domésticos. Cabe ainda observar que as diferenças raciais acentuam-se em determinadas regiões do país: elas eram mais elevadas nas regiões Sudeste, Sul e Centro-Oeste, nas quais o trabalho doméstico empregava respectivamente $25,1 \%, 24,5 \%$ e $23,7 \%$ da população negra feminina (IPEA et al., 2011). Como resultado, as mulheres negras representavam, em 2009, 61\% da mão-de-obra feminina ocupada no trabalho doméstico (IPEA, 2011).

Entendida como herança da escravidão, a menor escolarização e maior inserção da população negra em contextos de pobreza, em relação à população branca, são frequentemente mencionadas como fatores explicativos exclusivos da acentuada concentração das mulheres negras no trabalho doméstico e de cuidado. Tal entendimento contraria os achados da vertente sociológica que, a partir de 1970, identificou por meio de estudos quantitativos que a raça/cor - e não apenas a classe social - é determinante na posição dos indivíduos na sociedade brasileira (Hasenbalg, 1979; Oliveira et al., 1985; Berquó, 1988; Silva e Hasenbalg, 1992). O preconceito e a discriminação racial não são apenas um resquício do passado: raça, enquanto categoria social, adquiriu no decorrer da história funções e significados específicos, que estão entremeados ao funcionamento do capitalismo brasileiro.

Além disso, a progressiva elevação dos níveis de escolaridade das mulheres negras possibilitou a este grupo populacional atingir níveis em média maiores do que aqueles alcançados pelos homens negros. A transformação, sem dúvida significativa, não foi capaz de reverter quadros de exclusão social que atingem ainda preferencialmente as mulheres negras: este é o grupo que apresenta o menor rendimento e maior índice de pobreza na sociedade brasileira, e também apresenta menores níveis salariais que homens brancos, mulheres brancas e homens negros, mesmo quando considerada a mesma faixa de escolaridade (Paixão et al., 2011). Tampouco a maior escolarização foi capaz de reverter a concentração de mulheres negras no desempenho dos trabalhos domésticos.

Há, portanto, a necessidade de se pensar a vinculação entre feminilidade negra e trabalho doméstico a partir de uma perspectiva que considere também uma associação simbólica entre a categoria social "mulheres negras" e as tarefas cotidianas de cuidado e manutenção do lar, e que já foi constatada por autoras como Lélia González (1983) e bell hooks (1995). Mais do que isso, é necessário procurar compreender como tais associações construíram-se e modificaram-se historicamente e como se conjugam a fatores econômicos e sociais na criação de hierarquias entre grupos sociais distintos. Não fazê-lo significa adotar, ainda que de forma não intencional, o argumento de que a inserção desigual da população negra (e feminina) no mercado de trabalho (e no trabalho doméstico e de cuidado) deriva de problemáticas internas à população negra, e não de dinâmicas e construtos simbólicos, políticos e econômicos que são coletivamente articulados e partilhados (Bento, 1995; Pinto, 2012). 
O recurso a dados adicionais sobre a ocupação indicam alguns caminhos possíveis de reflexão. Segundo o IPEA (2011), ao considerar a distribuição da população por setor de atividade, é possível identificar que "as mulheres, especialmente as negras, estão mais concentradas no setor de serviços sociais (cerca de 34\% da mão de obra feminina), grupo que abarca os serviços de cuidado em sentido amplo (educação, saúde, serviços sociais e domésticos)" (IPEA, 2011: 27). Mesmo entre as mulheres negras que atingem o ensino superior, a tendência mantém-se: elas estão mais concentradas em áreas como enfermagem, fisioterapia e serviço social, que ocupam no mercado de trabalho posições de menor prestígio social e remuneração, implicam em uma relativa subordinação e ainda estão vinculadas ao cuidado e ao servir (Querino et al., 2011).

Também a exposição de dados de censos demográficos de períodos históricos anteriores agrega novos elementos para se pensar o cenário do trabalho doméstico no Brasil atual. O primeiro Recenseamento Geral do Brasil data de 1872 e, embora não apresente os dados de ocupação da população residente desagregados por raça/cor, faz distinção entre escravos/escravas e livres. Da população de mulheres escravas, $24,3 \%$ dedicavamse ao serviço doméstico, percentual superado apenas pelo número de cativas dedicadas à lavoura (57,1\%). Ausente nos Censos de 1900 e 1920, o quesito "cor" voltou a ser incorporado ao Censo de 1940. Os dados de então classificam conjuntamente serviços domésticos e atividades escolares, setor no qual se empregavam $11,7 \%$ das ocupadas brancas e $24,8 \%$ das pretas, pardas e de cor não declarada (Paixão et al., 2011). Existem, de fato, diferenças metodológicas significativas na coleta de dados em períodos distintos. Contudo, não deixa de ser notável a semelhança do retrato apresentado pelos censos de $1872 / 1940$ e pelos dados atuais ( $21,8 \%$ das mulheres negras e $12,6 \%$ das mulheres brancas ocupadas eram trabalhadoras domésticas).

Ademais, sublinha-se que mesmo entre mulheres de classes baixas, brancas e negras, sediadas em empregos domésticos e de cuidado existem diferenças significativas. Dados analisados pelo IPEA indicam que a remuneração média das trabalhadoras domésticas negras era de $R \$ 364,84$ em 2009; essa média para as brancas empregadas na mesma função e no mesmo período era de $R \$ 421,58$. Em 2009, a taxa de formalização de mulheres empregadas com tarefas domésticas era sempre menor que $30 \%$; contudo, entre mulheres negras essa taxa era de $24,6 \%$, comparado a $29,3 \%$ das mulheres brancas (Pinheiro et al., 2011).

Para além das desigualdades de salário e condições de trabalho internas às funções de trabalho reprodutivo, estudiosas do care têm encontrado pistas sobre distintas elaborações simbólicas sobre mulheres brancas e negras alocadas nessas funções. Guita Debert (2013) analisa a realidade das trabalhadoras importadas pela classe média italiana. De acordo com contratantes de cuidadoras de idosos entrevistadas pela autora, as mulheres africanas são as preferidas no desempenho de tarefas domésticas, com base no entendimento de que "esses trabalhos requerem mais energia e força física" (Debert, 2013: 17).

A despeito das diferenças contextuais, sobrepõem-se representações semelhantes sobre mulheres africanas ou afrodescendentes em situações diaspóricas. Observa-se que muito distantes do ideário de fragilidade física que os estudos de gênero identificam 
como associados às mulheres, as mulheres negras são retratadas como fisicamente fortes, naturalmente talentosas para atividades braçais e agressivas. Trata-se, como já assinalado por hooks (1995: 486), de uma imagem de "presença feminina 'natural', orgânica, mais próxima da natureza, animalesca e primitiva".

A perenidade com que as mulheres negras têm estado associadas ao trabalho doméstico ampara-se em mecanismos sutis de perpetuação de representações e dinâmicas que, sem precisar enunciar abertamente a vinculação da feminilidade negra ao desempenho das tarefas de trabalho doméstico e cuidado, não deixam por isso de moldar subjetividades e estruturar relações interpessoais e sociais.

Mediante os elementos elencados, faz-se necessário aprofundar as reflexões sobre o entrecruzamento de gênero e raça, de modo a tornar visível como ele configura uma divisão racial do trabalho com impactos na experiência social de distintos grupos de mulheres. Sobretudo, é preciso fomentar análises sobre os cuidados que os reconheçam, como ponto de partida, não apenas como trabalho genderizado, mas também como trabalho racializado, o que permitirá flagrar as nuanças da operação do atributo racial na organização social do cuidado.

\section{Care e a divisão racial do trabalho}

No decorrer deste artigo, apontamos que a associação entre emprego doméstico e raça demanda compreensões que ultrapassam os argumentos exclusivamente econômicos ou a instrução formal dos distintos grupos raciais. Existem associações simbólicas que, em conjunto com fatores econômicos, sociais e culturais, seguem perpetrando determinadas imagens acerca do trabalho doméstico, de sua característica intrínseca de subserviência e de quais mulheres são ideal e "naturalmente" aptas para os mesmos.

Ao reconhecer a raça como uma categoria relevante para a compreensão dos parâmetros conforme os quais se organiza socialmente o trabalho de cuidado, detemonos nessa estruturação triangular entre diversas atribuições de reprodução social divididas entre homens e mulheres e entre mulheres brancas e mulheres negras, procurando recuperar e também forjar chaves analíticas que evidenciem as interconexões entre gênero e raça.

Em estudos sobre o care e acerca das atribuições de reprodução social entre homens e mulheres, evidencia-se de pronto que existe uma divisão entre esses personagens que pouco mudou no que se refere ao cuidado com a casa e com as pessoas, a despeito das grandes transformações observadas quanto à inserção das mulheres no mercado de trabalho. A categoria analítica de gênero, então, é citada em quase todos os trabalhos de referência nessa área, sendo bem sublinhado que a reprodução social e as famílias continuam sendo um lócus privilegiado das estruturações da experiência (e desigualdades) de gênero. Por outra feita, existe uma conexão também aclamada sobre o trabalho doméstico remunerado no Brasil ser desempenhado majoritariamente por mulheres negras e ao fato de que essas têm suas subjetividades constituídas em meio a uma série de produções simbólicas sobre relações de subserviência. 
Menos comum, no entanto, é uma reflexão que conecte uma realidade à outra. Como já discutido, Hirata e Kergoat apontam para um acirramento hierárquico entre mulheres, referindo-se a realidades de países desenvolvidos e a fluxos migratórios de trabalho doméstico. Para essas autoras, a falta de mudanças significativas nas divisões de tarefas de reprodução social fez com que o sucesso das mulheres casadas e com filhos nas suas carreiras profissionais e de estudos dependesse da delegação de tarefas.

Em relação ao Brasil, a possibilidade de que as classes médias continuem mantendo-se e, principalmente, mantendo suas famílias heteronormativas, com filhos bem atendidos de cuidados, mulheres trabalhando fora e maridos pouco ativos na esfera doméstica, às voltas com um Estado pouco afeito a políticas de cuidado, é a possibilidade de delegar essas tarefas para outras mulheres - mulheres negras. Como indicado por Sandra Azerêdo (1989), a divisão racial do trabalho doméstico constitui um lócus privilegiado para a observação da separação - ou das diferenças - entre mulheres.

A aclamada hierarquia entre gêneros deve ser situada por meio de considerações acerca das vivências distintas para mulheres brancas e negras. A oposição simples de gênero invisibiliza o fato de que determinados aspectos da experiência cotidiana de trabalho doméstico e de cuidado são minimizados para mulheres brancas e de classes médias e altas, com base na possibilidade de transferir boa parte de suas responsabilidades com a reprodução social para a figura das empregadas domésticas. A divisão sexual do trabalho é mantida pela divisão racial do serviço doméstico e de cuidado.

Bastante comum, no Brasil, encontrar operadores de ensino, direito, justiça, saúde, etc. citarem a "desestruturação familiar" como a causa principal dos problemas enfrentados por adolescentes - principalmente quando envolvidos com drogas, violência urbana e baixo desempenho escolar (Abramovay, Cunha e Calaf, 2009). Sem discutir a amplitude e insistência com que se tem consagrado um determinado modelo normativo de família como único espaço ideal de subjetivação e reprodução social, destacamos que o tempo imaginado para que mães passem com seus filhos e os eduquem da forma modelar é muito relativo. As mulheres brancas inseridas no mercado de trabalho não possuem tempo para desempenhar essas tarefas sozinhas, poucas têm auxílio de seus maridos e muitas trazem mulheres negras para suas casas - as quais possibilitam que uma estrutura de cuidados determinada coexista com a busca de sucesso profissional e desenvolvimento pessoal por parte das mulheres brancas. As famílias das mulheres negras, em contrapartida, encontram-se despojadas em boa parte do tempo daquelas que constituem muitas vezes a única figura parental e potencial cuidadora, bem como permanecem alijadas de serviços públicos (escassos) ou privados (onerosos) que poderiam suprir tal demanda.

As tarefas domésticas são estruturantes das relações desiguais entre homens e mulheres e a família, assim, é um lócus privilegiado das estruturações de gênero. A divisão hierárquica entre mulheres, com base na raça e na classe social, não está dissociada dessa configuração de cuidados com a casa e com as pessoas. Pelo contrário, as lógicas hierárquicas somam-se e ponderam-se, elaborando de forma bastante complexa um esquema de assujeitamento de gênero envolvendo experiências sociais e 
subjetivas cortadas pela necessidade de dar conta da casa e das pessoas para que famílias no modelo ideal possam existir para um determinado segmento social.

É importante apontar que a segmentação racial do trabalho é ilustrativa de como, para além do status subalterno de gênero, as diferentes inserções sociais de brancas e negras, articuladas em torno do atributo racial, formatam desigualdades. Muitas vezes, os papéis sociais e tarefas associadas às feminilidades brancas e às feminilidades negras operam de forma dialógica e complementar, naquilo que constitui o âmbito mais geral do que se entende como feminino - o que não exclui, obviamente, a existência de sobreposições e rearticulações. Essa lógica funda hierarquias que operam na constituição de relações de exploração e que configuram subalternidades e também privilégios.

Ao observar tais relações, tende-se em geral a notar apenas a distância da experiência social entre distintos grupos de mulheres, como se o problema dissesse respeito apenas a mulheres. Entretanto, cabe observar que seu alcance é muito mais extenso e formata as relações entre todos os grupos sociais, resultando em impactos coletivos e difusos. Como buscamos indicar, a delegação de tarefas domésticas e de cuidado às mulheres negras, em nosso país, remonta à constituição da miscigenação física e cultural, que emerge como fundamento identitário da nação brasileira. Assentada em tão sólida referência, ela desempenha funções relevantes tanto na perpetuação da divisão sexual, quanto na segregação racial do trabalho.

Por outro lado, não se pode deixar de indicar que a operação constante e vigorosa da lógica a que nos referimos somente se torna possível dentro de um cenário em que são escassas e insuficientes as iniciativas para a desprivatização dos trabalhos domésticos e de cuidado e inexistentes aquelas que buscam redistribuir o trabalho de cuidado entre homens e mulheres, de modo que o exercício de tais funções por grupos subalternizados figura como condição indispensável para o desempenho do trabalho tido como efetivamente produtivo - ao menos nos moldes com que ele se desenvolve atualmente.

Com esse artigo procuramos estabelecer conexões entre subjetividades hierarquizadas, inseridas em um contexto amplo de atribuições de papéis de reprodução social. Em paralelo à abertura de espaço a uma discussão importante e ainda pouco esmiuçada por pesquisadoras e pesquisadores atentas/os a refletir sobre cuidado, gênero e relações raciais, procuramos chamar atenção para uma agenda de pesquisa. Sugerimos que tais conexões demandam elaborações de diversos tipos, levando em conta as novas propostas legislativas e de políticas públicas, como, por exemplo, as iniciativas de regulamentação do trabalho doméstico; além de olhares empíricos diversificados.

\section{BIBLIOGRAFIA}

Abramovay, Miriam; Cunha, Anna Lúcia e Calaf, Priscila Pinto (2009): Revelando tramas, descobrindo segredos: violência e convivência nas escolas. Rede de Informação 
Tecnológica Latino-americana - RITLA, Secretaria de Estado de Educação do Distrito Federal - SEEDF, Brasília.

Aguiar, Neuma (1981): “Um Guia Exploratório para a Compreensão do Trabalho Feminino", em Anuário Ciências Sociais Hoje, Vol. 1, 1981, p.3-15.

Arriagada, Irma (2004): "Cambio de las familias en el marco de las transformaciones globales: necesidad de políticas públicas eficaces", em Serie Seminarios y Conferencias No. 42 (LC/L.2230-P). Santiago de Chile: CEPAL, Publicación de las Naciones Unidas.

Azerêdo, Sandra (1989): "Relações entre empregadas e patroas: reflexões sobre o feminismo em países multirraciais", em Costa e Bruschini. (orgs.): Rebeldia e submissão: estudo sobre a condição feminina, p.195-220. São Paulo: Vértice.

Bandeira, Lourdes (2010): "Importância e motivações do Estado Brasileiro para pesquisas de uso do tempo no campo de gênero", em Revista Econômica, Vol. 12, No. 1, p.47-63.

Bastide, Roger e Fernandes, Florestan (1955). Relações raciais entre negros e brancos em São Paulo: ensaio sociológico sobre origens, as manifestações e os efeitos do preconceito de cor no município de São Paulo. São Paulo: Anhembi.

Bento, Maria Aparecida Silva (1995): "A mulher negra no mercado de trabalho", em Revista Estudos Feministas, Vol. 3, No. 2,p.479-488.

Bernardino-Costa, Joaze (2012): "Migração, trabalho doméstico e afeto", em Cadernos Pagu, No. 39, p.447-459.

Berquó, Elza (1988): “Demografia da desigualdade”, em Novos Estudos Cebrap, No. 21. p.74-85.

Camarano, Ana Amélia (2012): “Cuidados de longa duração para a população idosa: um novo risco social a ser assumido?", em Hirata e Guimarães (org.): Cuidado e cuidadoras: as várias faces do trabalho de care, p.148-165. São Paulo: Atlas.

(2007): "Instituições de longa permanência e outras modalidades de arranjos domiciliares para idoso", em Néri: Idosos no Brasil: vivências, desafios e expectativas na terceira idade, p.169-190. São Paulo: Edições SESC-SP; Editora Fundação Perseu Abramo.

Carrasco, Cristina; Borderías, Cristina e TORNS, Teresa (eds.) (2011). El trabajo de cuidado: historia, teoria y políticas. Madrid: Catarata.

Duffy, Mignon (2007): “Doing the Dirty Work: Gender, Race, and Reproductive Labor in Historical Perspective", em Gender \& Society, Vol. 21, No. 3, p.313-336. 
Debert, Guita Grin (2013): "Gênero, Velhice e Migrações", em Anais VII Congresso Latino-Americano de Estudos do Trabalho. O Trabalho no Século XXI. Mudanças, impactos e perspectivas. Grupo de trabalho 5: Trabalho de Cuidado.

Fernandes, Florestan (1978). A integração do negro na sociedade de classes. São Paulo: Ática.

Fontoura, Natália et.al(2010): "Pesquisas de uso do tempo no Brasil: contribuições para a formulação de políticas de conciliação entre trabalho, família e vida pessoal", em Revista Econômica, Vol. 12, No.1, p.11-46.

Freyre, Gilberto (2003): Casa grande e senzala: formação da família brasileira sob o regime da economia patriarcal. São Paulo: Global.

Giacomini, Sônia Maria (1988): Mulher e escrava: uma introdução histórica ao estudo da mulher negra. Petrópolis, RJ: Vozes.

(2006): A alma da festa: família, etnicidade e projetos num clube social da Zona Norte do Rio de Janeiro - O Renascença Clube.Belo Horizonte: Editora UFMG; Rio de Janeiro: IUPERJ.

Glenn, Evelyn Nakano (1992): "From servitude to service work: historical continuities in the racial division of paid reproductive labor", em Signs, Vol. 18, No.1, p.1-43.

Glucksmann, Miriam (2012): "Rumo a uma sociologia econômica do trabalho do care: comparando configurações em quatro países europeus", em Hirata e Guimarães (org.): Cuidado e cuidadoras: as várias faces do trabalho de care,p.63-78. São Paulo: Atlas.

González, Lélia (1983): "Racismo e Sexismo na Cultura Brasileira", em Silva et al. Movimentos sociais urbanos, minorias étnicas e outros estudos. Brasília: ANPOCS.

Gutiérrez-Rodrigues, Encarnación (2013): “Trabajo doméstico-trabajo afectivo: sobre heteronormatividad y la colonialidad del trabajo en el contexto de las políticas migratórias de la UE", em Revista de Estudios Sociales, No. 47, p.123-134.

Hasenbalg, Carlos (1979): Discriminação e desigualdades raciais no Brasil. Rio de Janeiro: Graal.

Hirata, Helena (2009). "A precarização e a divisão internacional e sexual do trabalho", em Sociologias, Porto Alegre, ano 11, No. 21, jan./jun., p. 24-41.

Hirata, Helena e Guimarães, Nadya Araújo (org.) (2012): Cuidado e cuidadoras: as várias faces do trabalho de care. São Paulo: Atlas. 
Hirata, Helena e Kergoat, Danièle (2007): "Novas configurações da divisão sexual do trabalho", em Cadernos de Pesquisa, Vol. 37, No. 132, p. 595-609.

Hochschild, Arlie (2003): "Travail émotionnel, règles de sentiments et structure sociale", em Travailler, Vol. 1, No. 9, p.19-49.

Hooks, Bell (1995): "Intelectuais negras", em Revista Estudos Feministas, Vol. 3, No. 2, p.464-478.

Ianni, Otávio (1972). Raças e classes sociais no Brasil. Rio de Janeiro: Civilização Brasileira.

IPEA (2011): Situação atual das trabalhadoras domésticas no país. Comunicados do IPEA No. $90 . \quad$ Disponível em: http://www.ipea.gov.br/portal/images/stories/PDFs/comunicado/110505 comu nicadoipea90.pdf.

IPEA et al (2011): Retrato das desigualdades de gênero e raça - 4a. ed. Brasília: IPEA, 2011.

Kofes, Suely (2001): Mulher, mulheres: identidade, diferença e desigualdade na relação entre patroas e empregadas domésticas. Campinas-SP: Editora da Unicamp.

Lagarde, Marcela (2003): “Mujeres cuidadoras: entre la obligación y la satisfacción”, em Congreso Internacional SARE 2003: Cuidar cuesta: costes y beneficios del cuidado.

Lisboa, Teresa Kleba (2003): “Fluxos migratórios de mulheres para o trabalho reprodutivo: a globalização da assistência”, em Revista Estudos Feministas, Vol. 15 , No. 3, p.805-821.

Machado, Maria Helena (2012). "Entre dois Beneditos: histórias de amas de leite no ocaso da escravidão", em Xavier, Farias e Gomes (orgs.): Mulheres negras no Brasil escravista e no pós-emancipação, p.199-213. São Paulo: Selo Negro.

Melo, Hildete Pereira de; Considera, Cláudio Monteiro e Di Sabbato, Alberto (2007): “Os afazeres domésticos contam", em Economia e Sociedade, Vol.16, n.3, p.435-454.

Molinier, Pascale (2004): "O ódio e o amor, caixa preta do feminismo? Uma crítica da ética do Devotamento", em Psicologia em RevistaVol. 10, No. 16, p.227-242.

Moreira, Núbia Regina (2007): “O feminismo negro brasileiro: um estudo do movimento de mulheres negras no Rio de Janeiro e São Paulo". Tese (Mestrado em Sociologia). Campinas-SP: Unicamp, Instituto de Filosofia e Ciências Humanas.

Motta, Alda Britto (1992): "Emprego doméstico: revendo o novo", em Caderno CRH, No. 16,p.31-49. 
Moutinho, Laura (2004): Razão, "cor" e desejo: uma análise comparativa sobre relacionamentos afetivo-sexuais "inter-raciais" no Brasil e na África do Sul. São Paulo: UNESP, 2004.

Oliveira, Lúcia et al. (1985): O lugar do negro na força de trabalho. Rio de Janeiro: IBGE.

Paixão, Marcelo et al. (orgs.) (2011): Relatório anual das desigualdades raciais no Brasil; 2009-2010: Constituição cidadã, seguridade social e seus efeitos sobre as assimetrias de cor ou raça. Rio de Janeiro: Garamond, 2011.

Parreñas, Rhacel Salazar (2012): "O trabalho de care das acompanhantes. Imigrantes filipinas em Tóquio", em Hirata e Guimarães (org.): Cuidado e cuidadoras: as várias faces do trabalho de care, p.201-215. São Paulo: Atlas.

Pinheiro, Luana et al. (2011): "Situação atual das trabalhadoras domésticas no país", em Mori et al. (orgs.): Tensões e experiências: um retrato das trabalhadoras domésticas de Brasília e Salvador. Brasília: Cfemea: MDG3 Fund.

Pinto, Elisabete Aparecida (2012): Mulher negra e o emprego doméstico: a travessia pelo século XX e as novas perspectivas para o século XXI [on line]. Disponível em: http://www.cnte.org.br/index.php/secretaria-de-relacoes-degenero/artigos/9790-mulher-negra-e-o-emprego-domestico-a-travessia-peloseculo-vinte-e-as-novas-perspectivas-para-o-seculo-xxi.html.

Querino, Ana Carolina et al. (2011): "Gênero, raça e educação no Brasil contemporâneo: desafios para a igualdade", em Bonetti e Abreu: Faces da desigualdade de gênero e raça no Brasil,p.129-147, Brasília-DF: IPEA.

Silva, Nelson do Valle e Hasenbalg, Carlos (orgs.) (1992): Relações raciais no Brasil contemporâneo. Rio de Janeiro: Rio Fundo/IUPERJ.

Sorj, Bila (2010): "Os cuidados com a família e as desigualdades de gênero e de classe", em Costa et al. (org.s): Divisão sexual do trabalho, Estado e crise do capitalismo. Recife: SOS Corpo.

Sorj, Bila e Fontes, Adriana (2012): "O care como regime estratificado: implicações de gênero e classe social", em Hirata e Guimarães (orgs.): Cuidado e cuidadoras: as várias faces do trabalho de care, p.103-116. São Paulo: Atlas.

Souza, Flávia Fernandes de (2012): "Escravas do lar: as mulheres negras e o trabalho doméstico na Corte Imperial", em Xavier; Farias e Gomes (orgs.): Mulheres negras no Brasil escravista e no pós-emancipação, p.244-260. São Paulo: Selo Negro. 
Sunkel, Guillermo (2006): "El papel de la familia en la protección social en la América Latina", em Serie Políticas Sociales No. 120 (LC/L.2530-P/E). Santiago de Chile: CEPAL, Publicación de las Naciones Unidas.

Fecha de recepción: 3 de Julio del 2014

Fecha de aprobación: 22 de octubre de 2015 